\title{
The Role of Electron-Emitting Radiopharmaceuticals in the Palliative Treatment of Metastatic Bone Pain and for Radiosynovectomy: Applications of Conversion Electron Emitter Tin-117m
}

\author{
Suresh C. Srivastava* \\ Brookhaven National Laboratory, Medical Department, Building 801, P.O. Box 5000, Upton, suresh@bnl.gov; \\ 11973-5000, New York - USA
}

\begin{abstract}
A variety of radionuclides continue to be investigated and/or clinically used for different therapeutic applications in nuclear medicine. The choice of a particular radionuclide with regard to appropriate emissions, linear energy transfer (LET), and physical half-life, etc., is dictated to a large extent by the character of the disease (e.g., solid tumor or metastatic disease), and by the carrier to selectively transport the radionuclide to the desired site. An impressive body of information has appeared in the recent literature that addresses many of these considerations. This article summarizes and discusses the role of high-LET electron emitters and their advantage in the treatment of cancer or for other disorders in specific situations. Areas such as bone pain palliation, bone malignancy therapy, and radiation synovectomy are covered in greater detail. Projections are made as to the future directions and progress in these areas. A discussion of the various issues related to the selection criteria that are useful for choosing the appropriate radionuclide for a particular application is included. Use of high-LET electron emitters is discussed in greater detail, with particular emphasis on the use of conversion electron emitter tin-117m for various therapeutic applications.
\end{abstract}

Key words: Radionuclide therapy, Conversion electron emitters, Bone pain palliation, Radiosynovectomy, Tin- $117 \mathrm{~m}$.

\section{INTRODUCTION}

During the past several years, a number of excellent publications have covered the many new and exciting developments in the rapidly advancing field of radionuclide therapy. These articles have provided an outline of the principles for production, and decay considerations for therapeutic radionuclides (Volkert et al., 1991), clarified the relationships between tumor size and curability for therapy with beta-emitting radionuclides (Wheldon, 1994; O'Donoghue et al., 1995), and set the criteria for the selection of radionuclides for cancer radioimmunotherapy (Mausner and Srivastava, 1993; Srivastava, 1996). A recent review describes the developments in the application of therapeutic radiopharmaceuticals in preclinical studies, as well as in the clinical setting (Ercan and Caglar, 2000; Srivastava, 2002).

Nuclear medicine has indeed experienced a resurgence of interest in radiotherapeutic procedures. Using unsealed sources for

\footnotetext{
${ }^{*}$ Author for correspondence
} 
radionuclide therapy is not a new concept; it has been around for over five decades starting with the development of the treatment of thyroid disorders with radioiodine. However, recent advances in molecular biology have led to a better understanding of cancer. Parallel research has shown promise for monoclonal antibodies, peptides, and other biological vehicles to serve as specific carriers to deliver cell killing radiation into tumors in a highly localized fashion. These developments have led to a renewed interest in the exciting possibility of treating human malignancies with the systemic administration of radionuclides. A number of other relatively new techniques such as the treatment of metastatic bone pain, radiation synovectomy, bone marrow ablation, and others, have given additional impetus to need for research on therapeutic radionuclides tailored for specific applications. A major advantage of radionuclides is that they emit radiation of different radiobiological effectiveness and range of action. This offers the possibility of choosing a nuclide the physical and nuclear characteristics of which are matched with a particular tumor type, or the disease under treatment.

The desirable therapeutic radionuclide should have particulate emission ( $\beta^{-}$, conversion electron, Auger electron, or alpha emission) suited to the nature and stage of the disease, in sufficient abundance. A gamma emission component, in reasonable abundance, can be of advantage for low-dose imaging especially during staging, for dosimetry estimates, and for monitoring response to therapy. A physical half-life of 1-14 d (preferably with stable daughter products) is optimal; it should be matched with the in-vivo pharmacokinetics of the isotope-carrier vehicle combination. The radioelement's chemistry should be amenable for its attachment with a broad class of compounds with high in-vivo stability. Finally, a free or chelated radionuclide should be excreted rapidly following metabolic processes, and should have little or no affinity for blood or normal body tissues. Although only few existing isotopes meet all of these criteria, there are a number of emerging "new" radionuclides that appear promising and versatile, and warrant continued investigations (Srivastava, 1996a; Srivastava, 1999). A list of current as well as future therapeutic radionuclides, chosen arbitrarily on the basis of particle emission and a few other parameters, is presented in Table 1. The nature of the delivery vehicle depends upon the mechanisms that could be used to selectively target lethal doses of the radionuclide to the diseased tissue. A few representative examples, for cancer therapy, are shown schematically in Fig. 1.

The choice of a radionuclide best suited for a specific application depends on a number of factors (Srivastava, 1996a; Ercan and Caglar, 2000; Srivastava, 1996b; Srivastava, 1999). These include: i) half-life, ii) type of emission $(\alpha, \beta, \gamma$, Auger or conversion electrons), iii) specific activity, iv) binding- or coordination-chemistry, v) route of administration, vi) internal dosimetry, vii) radiation safety and environmental concerns, viii) vehicles used as the carrier, ix) biopharmacokinetics of the labeled carrier and the free nuclide, and $\mathrm{x}$ ) cost of production and availability. Until very recently, a majority of clinical trials have used primarily I-131 and Y-90, two isotopes that have less than ideal therapeutic properties for most applications, but have been available at reasonable cost with some degree of regularity. A number of other isotopes seem to offer much better properties for specific applications. These include: Auger and CE emitters Ga-67, Br-77, Tl-201, Sn-117m, I-123, I$125, \mathrm{Hg}-195 \mathrm{~m}$, and Pt-195m; $\alpha$-emitters At-211, Bi-212, Bi-213, Ac-225, and Fm-255; and $\beta / \gamma$ emitters Sc-47, Cu-67, Sm-153, Ho-166, Lu-177, Re-186, Re-188, and Au-199.

Many others continue to be added to this list. Unfortunately, there is a lack particularly in the U.S., of a continuous and reliable supply, at reasonable cost, of many of these promising therapeutic isotopes (Aldestein and Manning, 1995). This situation has not only slowed research in this important area but has also continued to be a major obstacle for radionuclide therapy to assume a more widespread and useful role in clinical practice.

\section{Therapeutic Particle Emissions}

Therapeutic particle emissions consist of Auger electrons, alpha emission, beta particles, and conversion electrons. Except for the beta particles, all of these are classified as high-LET (linear energy transfer) electron emitters. Conversion electrons in addition are generally monoenergetic and they have a discrete range in tissue, as opposed to beta electrons that may have a range of energies, and thus a maximum and an average energy value. 


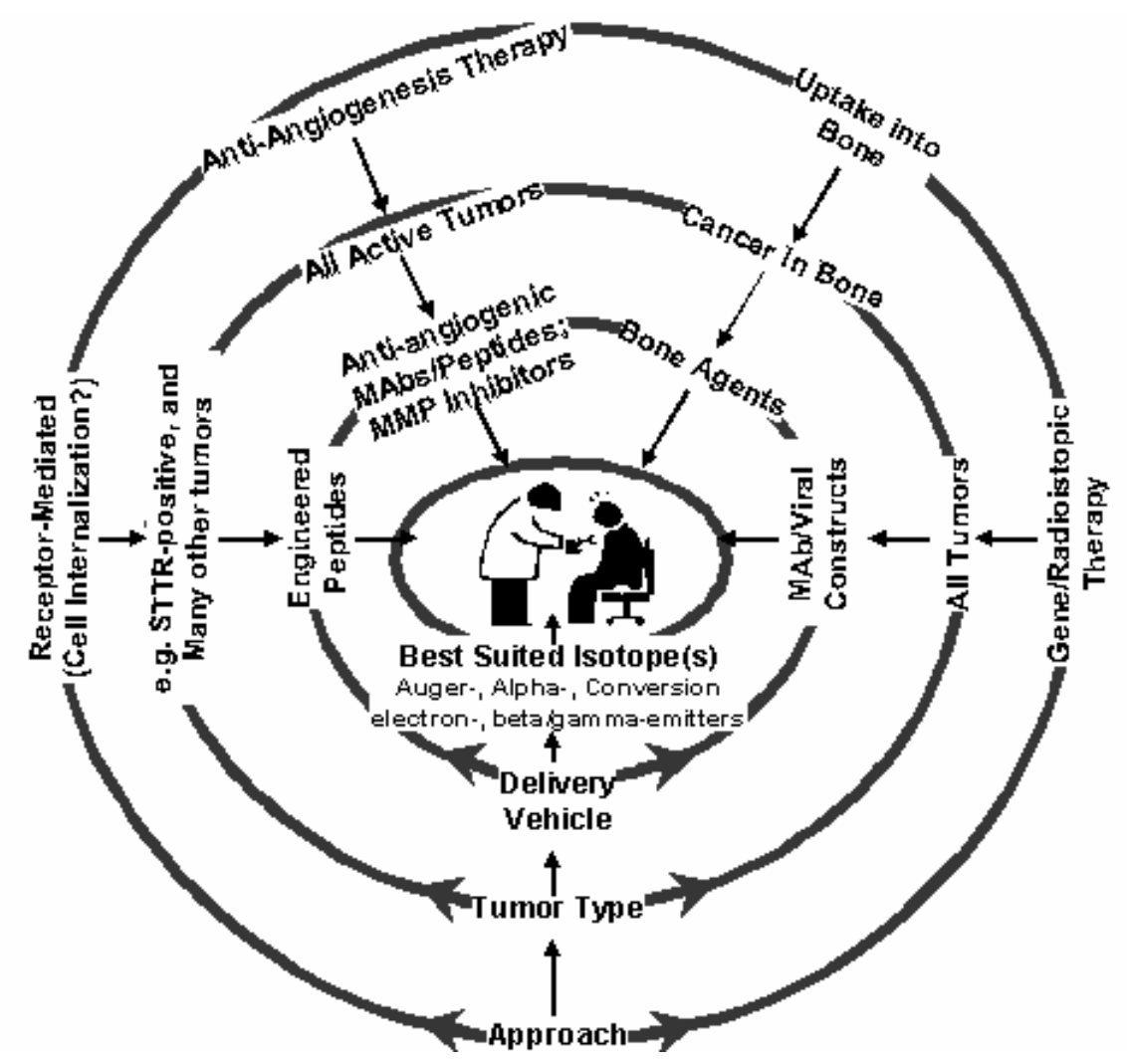

Figure 1 - Schematic Representation of the Central Role of Radionuclides for Certain Promising Approaches for Therapy of Cancer

Table 1 - Present and Future Therapeutic Radionuclides

\begin{tabular}{|c|c|c|c|c|}
\hline Nuclide & $\mathbf{T}^{1 / 2}$ & $\begin{array}{c}\text { Particle } \\
\text { Emission }\end{array}$ & $\begin{array}{c}\mathbf{E}_{\mathrm{avg}}, \mathbf{k e V}^{2} \\
(\% \text { per decay })\end{array}$ & $\begin{array}{c}\text { Principal gamma } \\
\text { component } E \text {, } \\
\operatorname{keV}(\%)\end{array}$ \\
\hline $\mathrm{P}-32^{3}$ & $14.3 \mathrm{~d}$ & B- & 695 & --- \\
\hline Sc-47 & $3.3 \mathrm{~d}$ & $\beta^{-}$ & 162 & $159(68)$ \\
\hline $\mathrm{Cu}-67$ & $2.6 \mathrm{~d}$ & $\beta^{-}$ & 141 & $185(49)$ \\
\hline Ga-67 & $3.3 \mathrm{~d}$ & Aug & $0.04-9.54(572)$ & $93(37)$ \\
\hline As-77 & $1.6 \mathrm{~d}$ & $\mathrm{~B}-$ & 228 & 239 (1.6) \\
\hline $\mathrm{Sr}-89^{3}$ & $50.5 \mathrm{~d}$ & B- & 583 & --- \\
\hline$Y-90^{3}$ & $2.7 \mathrm{~d}$ & $\beta^{-}$ & 935 & --- \\
\hline Rh-105 & $1.5 \mathrm{~d}$ & $\beta^{-}$ & 190 & 319 (19) \\
\hline Pd-109 & $0.6 \mathrm{~d}$ & $\beta^{-}$ & 360 & $88(4)$ \\
\hline Ag-111 & $7.5 \mathrm{~d}$ & $\beta^{-}$ & 350 & $342(7)$ \\
\hline In-111 & $2.8 \mathrm{~d}$ & Aug & $0.5-25(308)$ & $171(90) ; 245(94)$ \\
\hline $\mathrm{Sn}-117 \mathrm{~m}$ & $14.0 \mathrm{~d}$ & C.E. & $127 ; 152^{4}$ & $159(86)$ \\
\hline $\mathrm{I}-123$ & $13.2 \mathrm{~h}$ & Aug & $0.7-30(289)$ & $159(83)$ \\
\hline $\mathrm{I}-125$ & $60.1 \mathrm{~d}$ & Aug & $0.7-30(479)$ & $36(7)$ \\
\hline $\mathrm{I}-131$ & $8.0 \mathrm{~d}$ & $\beta^{-}$ & 181 & $364(81)$ \\
\hline Sm-153 & $1.9 \mathrm{~d}$ & $\beta^{-}$ & 225 & $103(28)$ \\
\hline Gd-159 & $0.8 \mathrm{~d}$ & $\beta^{-}$ & 311 & $363(8)$ \\
\hline Dy-165 & $2.33 \mathrm{~h}$ & $\beta^{-}$ & 438 & $95(4)$ \\
\hline Ho-166 & $1.1 \mathrm{~d}$ & $\beta^{-}$ & 666 & $80(6)$ \\
\hline
\end{tabular}




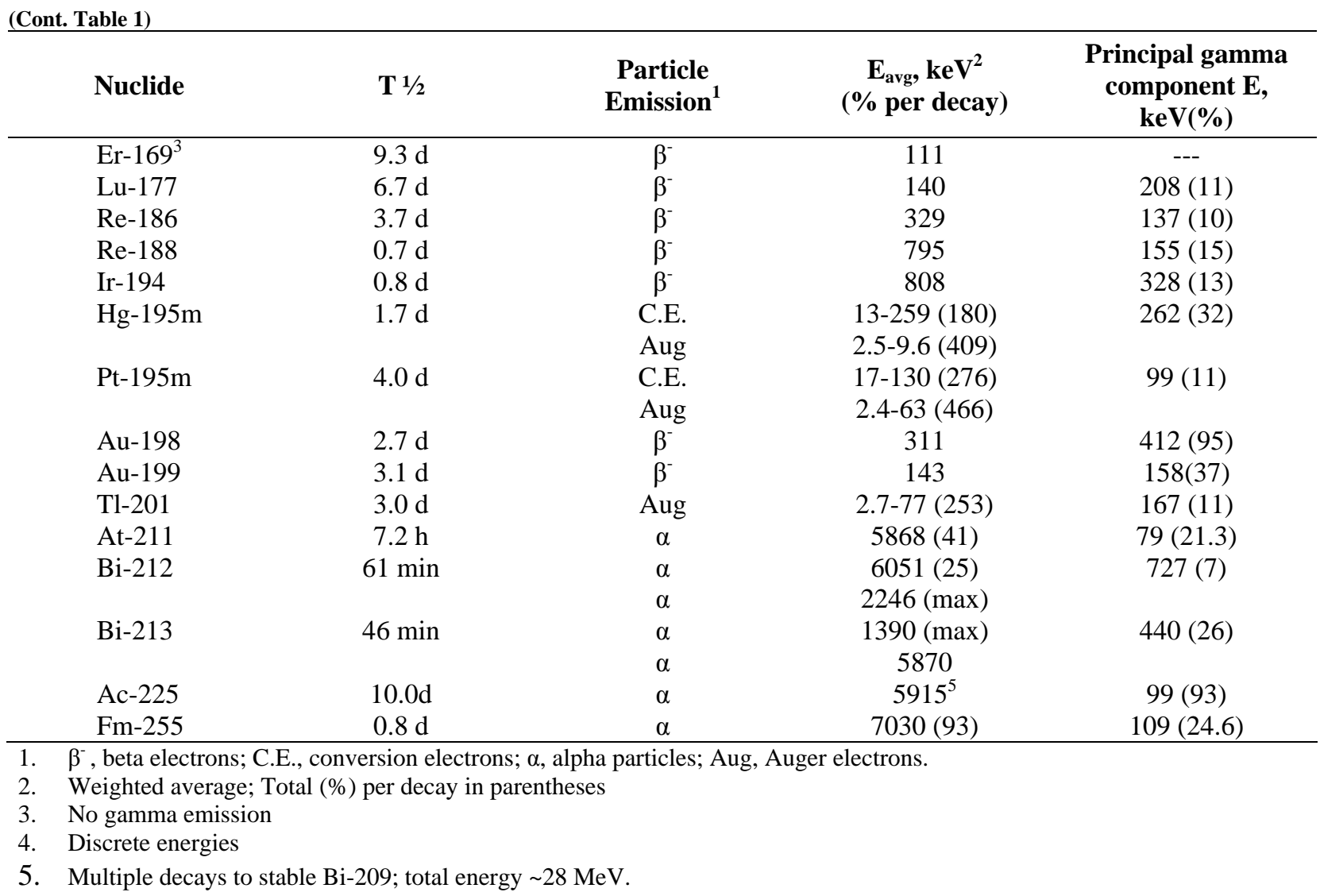

Auger electrons are very effective in cell kill but proximity to cellular DNA is often a necessary requirement. Alpha emitters are generally effective over several cell diameters (Mausner and Srivastava, 1993; Srivastava, 1996a; Ercan and Caglar, 2000; Srivastava, 1996b; Srivastava, 1999; Aldestein and Manning, 1995; Humm, 1986), whereas conversion electron emitters (depending upon energy) are effective over $0-50$ cell diameters. In general, all high-LET emitters are much more effective for small lesions and for micrometastatic disease. For example, with a decrease in tumor size from 1 to $0.2 \mathrm{~mm}$, the alpha emitter At-211 (energy transfer $\sim 80 \mathrm{keV} / \mathrm{mm}$ ) is 9 - 33 times more effective than the low LET $(\sim 1$ $\mathrm{keV} / \mathrm{mm}$ ) Y-90. At the cell surface, At-211 is 1200 times more effective than Y-90 [10]. Because of their shorter range, and since there is no or insignificant crossfire, high-LET emitters are less effective for large tumor masses and macrometastatic disease, even though the distribution within the lesion may be homogeneous. High-LET radiopharmaceuticals require a higher degree of selectivity of localization and this requires better and more specific targeting mechanisms. Ultimately, the selection of an appropriate particle emitter depends upon the nature, the extent, and stage of disease.

\section{Low-Energy Conversion Electron Emitters}

Conversion electrons by definition are associated with internal conversion which is an isoenergetic radiationless transition between two electronic states. Low-energy conversion electron emitters, e.g., tin- $117 \mathrm{~m}$ offer the best combination of properties (Table 2). Tin- $117 \mathrm{~m}$ emits short-range electrons with a high linear energy transfer, and thus a high $S$ value resulting in high quality therapeutic radiation. These properties translate into a very high localized dose to diseased tissue with minimal toxicity to normal organs or nontarget tissues. Commonly used beta emitters in comparison have much lower linear energy transfer and the emitted electrons resemble a plume that travels over a longer distance which translates into less intense localized therapeutic effect.

$\mathrm{Sn}-117 \mathrm{~m}$ can be produced in a reactor via neutron capture $[116 \operatorname{Sn}(n, \gamma) 117 \mathrm{mSn}]$ or via non-elastic 
neutron scattering [117Sn $\left.\left(\mathrm{n}, \mathrm{n}^{\prime}, \gamma\right) 117 \mathrm{mSn}\right]$ reactions. Because of low neutron capture crosssection, the first reaction doesn't allow production of high-specific activity Sn-117m. Reaction of Sn$117 \mathrm{~m}$ production from $\mathrm{Sn}-117$ is a threshold one and takes place in fast neutrons $\left(\mathrm{E}_{\mathrm{n}}>0.1 \mathrm{MeV}\right)$. The highest fast neutron fluxes - up to $2.10^{15} \mathrm{~cm}^{-2} \mathrm{~s}^{-}$ ${ }^{1}$ are available in the SM reactor at the Research Institute of Atomic Reactors (RIAR) in Dimitrovgrad, Russia, in specially designed holes in fuel assemblies. Therefore, irradiation positions in the active core of this reactor with the maximum fast neutron flux density were used for irradiation. An average cross section value of the production reaction was determined by averaging the energy dependence of the cross-section of inelastic neutron scattering on Sn-117 nuclei using calculated neutron spectra. For cells of active core of the SM reactor that value was found to be 140 millibarn. Using this value for calculations has demonstrated that in a regular reactor cycle (18 effective days) specific activity of Sn-117m can reach $17 \mathrm{Ci} / \mathrm{g}$ at EOB. Irradiation during two reactor cycles allows an increase in specific activity of up to $23 \mathrm{Ci} / \mathrm{g}$. Several experimental irradiations of $92 \%$ enriched tin-117 have confirmed the results of theoretical calculations (Toporov et al., 2006). Multi-curie amounts of this high-specific activity $\mathrm{Sn}-117 \mathrm{~m}$ are routinely available from RIAR, on a year-long basis.

Several methods to produce no-carrier-added (NCA) tin- $117 \mathrm{~m}$ have been attempted using proton induced reactions on Cd-114, In-115, and Cd-116 in an accelerator but all of these give low or unmeasurable yields. Using the BLIP at BNL, we had previously studied the [nat $\mathrm{Sb}(\mathrm{p}, 2 \mathrm{p} 3 \mathrm{n}$ or $\mathrm{p}, 2 \mathrm{p} 5 \mathrm{n}) 117 \mathrm{mSn}$ ] reactions using proton energies of 38-60 MeV. Cross sections of $5 \mathrm{mb}$, enough to produce therapeutic quantitities of $117 \mathrm{mSn}$ with high specific activity, were measured. The specific activity when assumed to be wholly dependent on the amount of tin impurity in the antimony target was calculated to be $30,000 \mathrm{mCi} / \mathrm{mg}$ for each part per million of tin in the target. However, further theoretical cross section calculations at the Institute of Nuclear Research (INR) in Troitsk, Russia (Ermolaev et al., 2006) have demonstrated that the proton energy range should be much broader, perhaps $40-130 \mathrm{MeV}$. The specific activity of Sn-117m depends mainly upon the amount of stable tin which is also generated during the irradiation of natural antimony. This can vary between $\sim 1000-3000 \mathrm{mCi} / \mathrm{mg}$ at $\mathrm{EOB}$, a range that is suitable for radiolabeling molecules that bind to saturable in-vivo receptors.

These studies are continuing and show great promise for the high-energy production of NCA tin- $117 \mathrm{~m}$ in multi-curie amounts for clinical therapeutic applications (Ermolaev et al., 2006).

At BNL, our work on radionuclide therapy has for some time focused on the development of tin$117 \mathrm{~m}$ for application to several distinct clinical areas. These include palliation of bone pain from osseous metastases, treatment of metastatic bone disease, radiation synovectomy, radioimmunotherapy, and cardiovascular applications. The first three of these areas are covered in this article in greater detail.

\section{Bone Pain Palliation}

Bone-seeking therapeutic radiopharmaceuticals are utilized on the basis of the therapeutic electron emissions of particular radionuclides, some of which may also emit imaging photon(s). The interest in application of radionuclides to therapy of bone malignancies, particularly for palliative relief of bone pain, is not new, but has recently undergone a renewal. It had its origin in the earliest days of the nuclear era but fell into relative obscurity for some time, until about a decade ago. Both strontium-89 and phosphorus-32 were investigated as early as the 1940's for the treatment of metastatic cancer to bone (Pecher, 1942; Friedell and Storaasli, 1950). The work of Firusian et al. (1976) suggested again that strontium-89 would be useful for relief of pain secondary to osseous metastases. Robinson and others further explored the utility of strontium-89 (Robinson, 1986; Quilty et al., 1994; Lewington et al., 1991; Robinson et al., 1987) resulting in the FDA approval for its routine application in 1993. This work has also stimulated clinical research in order to find other radionuclides, which may have improved physical properties that permit treatment with fewer side effects on the myeloproliferative cells in the bone marrow.

The basis for the action of these therapeutic agents is their incorporation into bone mineral and their beta emission, which limits their range of action to the near neighborhood of their increased concentration in pathological areas such as metastases where the attempt at healing by the bone results in increased uptake. Tin- $117 \mathrm{~m}$ is an exception in that its emission consists primarily of conversion electrons rather than beta particles (Table 2). Table 3 lists the currently used isotopes 
(either approved or being investigated) for bone pain palliation and their nuclear and physical characteristics. These same radionuclides, in addition to a few others described in a later section, also have properties that make them useful for radiosynovectomy.

The relevant physical characteristics of the various radionuclides are given in Table 3. Strontium-89 chloride (Metastron) and Samarium-153 EDTMP (Quadramet) have been approved by the Food and Drug Administration within the last ten years. Phosphorus-32 as sodium phosphate was grandfathered as an approved drug when the FDA took over jurisdiction of radiopharmaceuticals from the Atomic Energy Commission many decades ago. Since P-32 is often used as a baseline for comparison, it will be discussed first. Rhenium-186 (which is approved in many nonU.S. countries), Re-188- HEDP, and Tin- $117 \mathrm{~m}$ Stannic DTPA are still under investigation in the U.S. Other newer radiolanthanide metals, such as Ho-166, and Lu-177, etc. are also undergoing investigation but will not be covered here since there is a paucity of definitive clinical and pharmacokinetic information in the literature on these agents.

\section{Phosphorus-32}

Phosphorus-32 as sodium phosphate $\left(\mathrm{NaH}_{2} \mathrm{PO}_{4}\right)$, as mentioned earlier, was the earliest used agent for palliation of pain from osseous metastases. Originally it was believed that its effect was mainly from incorporation into the tumor itself. However, the tumor to non-tumor ratio is not very favorable and the relief of pain is primarily because of its uptake into bone mineral, not the tumor. In addition, uptake is higher in any rapidly dividing tissue such as bowel, but particularly so in the red marrow itself in addition to involved bone. Therefore, the bone to marrow ratio is low. Similar to Sr-89, P-32 has a highly energetic beta emission, and has no accompanying gamma photon making monitoring somewhat difficult. Results have been similar to Sr-89, but toxicity to the bone marrow has been severe at therapeutic level administrations. Phosphorus-32 has also been used in therapy of polycythemia vera and leukemia. Most of the information in patients in regard to localization and dosimetry has come from studies in such patients. However, there has been a revival of interest in $\mathrm{P}-32$ for bone pain palliation during the last few years. A recently completed IAEA clinical trial in a total of 93 patients (48 with intravenous strontium- 82 and 45 with orally administered phosphorus-32) claims to have demonstrated comparable effectiveness of P$32(60 \%$ response vs. $75 \%$ for $\mathrm{Sr}-89)$ for treating metastatic bone pain (Fettich et al., 2002). The myelotoxicity was slightly higher than with $\mathrm{Sr}-89$, but not intolerable. It remains to be seen if these results are confirmed by other investigators, and using a wider patient population.

\section{Strontium-89 chloride}

Strontium-89 is a pure beta emitter. The maximum beta energy is high and penetration (average) in soft tissue is $2.4 \mathrm{~mm}$. The long physical half-life means that low administered activity is given resulting in a rather low initial dose rate. In addition, it limits the possibility of repeat doses until much after the initial dosing. Nevertheless, it has proven effective (Lewington et al., 1991; Robinson et al., 1987; McEwan, 1994; Katin et al., 1993). Absence of an accompanying gamma photon makes it difficult, but not impossible, to monitor distribution. The energetic betas result in a low bone to marrow dose ratio but myelotoxicity has not been a major factor. While individual studies vary in results, the overall efficacy in terms of patients experiencing pain relief (complete + marked + moderate) appears to be in the range of $54 \%$ (Kennedy et al., 1941) to $80 \%$ (Robinson et al., 1987).

Table 2 - Decay Data for Tin- $117 \mathrm{~m}^{1}$ (Half-life 14.0 days) (Srivastava et al., 1985)

\begin{tabular}{lcc}
\hline Major Emissions & Energy, KeV & Intensity, \% \\
\hline Auger-L & 3.0 & 91.0 \\
Auger-K & 21.0 & 10.8 \\
$* \boldsymbol{C E}-\boldsymbol{K} \mathbf{1}$ & $\mathbf{1 2 6 . 8}$ & $\mathbf{6 4 . 8}$ \\
$\boldsymbol{C E}-\boldsymbol{K} \mathbf{2}$ & $\mathbf{1 2 9 . 4}$ & $\mathbf{1 1 . 7}$ \\
$\boldsymbol{C E}-\boldsymbol{L 1}$ & $\mathbf{1 5 1 . 6}$ & $\mathbf{2 6 . 1}$ \\
CE-L2 & 154.1 & 1.5 \\
CE-M1 & 155.1 & 5.6 \\
Gamma photon & 158.6 & 86.4 \\
\hline
\end{tabular}


Table 3 - Physical and nuclear characteristics of bone-seeking therapeutic radionuclides (Volkert et al., 1991)

\begin{tabular}{llcccl}
\hline & $\begin{array}{c}\text { Maximum } \boldsymbol{\beta}^{-} \\
\text {energy } \\
(\mathbf{M e V})\end{array}$ & $\begin{array}{c}\text { Average } \boldsymbol{\beta}^{-} \\
\text {energy } \\
(\mathbf{M e V})\end{array}$ & $\begin{array}{c}\text { Average } \\
\text { Range } \\
(\mathbf{m m})\end{array}$ & $\begin{array}{c}\mathbf{T}_{\mathbf{1} / 2} \\
(\mathbf{d a y s})\end{array}$ & $\begin{array}{c}\gamma \text { photon } \\
(\mathbf{M e V})\end{array}$ \\
\hline Strontium-89 & 1.46 & 0.58 & 2.4 & 50.5 & None \\
Phosphorus-32 & 1.71 & 0.70 & 3.0 & 14.3 & None \\
Tin-117m & $0.13^{2}$ & --- & 0.22 & 14.0 & $0.159(86 \%)$ \\
$0.15^{2}$ & -- & 0.29 & & & \\
Erbium-169 & 0.34 & 0.11 & 0.30 & 9.3 & None \\
Lutetium-177 & 0.50 & 0.14 & 0.35 & 6.7 & $0.208(11 \%)$ \\
Rhenium-186 & 1.08 & 0.33 & 1.05 & 3.7 & $0.137(9 \%)$ \\
Samarium-153 & 0.81 & 0.22 & 0.55 & 1.9 & $0.103(29 \%)$ \\
Holmium-166 & 1.84 & 0.67 & 3.3 & 1.1 & $0.081(6 \%)$ \\
Rhenium-188 & 2.12 & 0.64 & 3.8 & 0.71 & $0.155(10 \%)$ \\
\hline
\end{tabular}

${ }^{1}$ Arranged in order of decreasing half-life

${ }^{2}$ Conversion electrons with discrete energies (and range).

\section{Samarium-153 EDTMP}

This radiopharmaceutical has a short physical halflife of 1.9 days. This can be advantageous in that it is easier to administer repeated doses. However, it makes manufacturing and delivery a more difficult problem. The range of its beta particles is short (average $0.55 \mathrm{~mm}$ ) resulting in good bone to marrow ratios ranging between 2-5.5. Myelotoxicity has been manageable at the approved dose schedule $(1 \mathrm{mCi} / \mathrm{kg})$, and efficacy is in a similar range as $\mathrm{Sr}-89$ (Turner and Claringbold, 1991; Farhangi et al., 1992; Collins et al., 1993; Resche et al., 1997). At high levels of administered Sm-153, an increase in survival of patients with metastatic prostate cancer was demonstrated, but at the cost of severe myelotoxicity (Collins et al., 1993).

\section{Rhenium-186 HEDP}

The physical half-life of rhenium-186 is 3.7 days. This is long enough that shipment and shelf life are less of a problem than with samarium-153. It is short enough that repeated doses could be given over a relatively short period of time. However, the average beta energy is considerably higher than that of samarium-153, and consequently the range is longer so that, at least theoretically, it is less sparing of the bone marrow. However, dosimetry from Re-188-HEDP, a much higher energy beta emitter, was shown to be within acceptable limits (Liepe et al., 2003). The dose ratio of bone to marrow is not particularly favorable for Re-186 and the compound is less stable in vivo than the other radiopharmaceuticals under discussion (Maxon et al., 1990; de Klerk et al., 1992).

\section{Tin-117m Stannic DTPA}

At this time somewhat limited but sufficient clinical experience has been obtained with this compound (Atkins et al., 1993; Atkins et al., 1995; Krishnamurthy et al., 1997; Srivastava et al., 1998). Its physical characteristics are very favorable. The range of the electron emission (monoenergetic conversion electrons) is less than that of any of the other compounds so that the radiation absorbed dose to the marrow is considerably less, giving the best bone to marrow ratio (Table 4). The initial dose rate is higher than that obtained with strontium- 89 and the half-life is ideal so far as shipment and shelf life are concerned. Its in-vitro and in-vivo stability are very high (Srivastava et al., 1994). An accompanying gamma photon is useful for monitoring. Results from the clinical trials so far indicate a very low myelotoxicity (Table 4) and the efficacy is similar to the other compounds (Srivastava et al., 1998).

Tin-117m differs from the other therapeutic agents in that its primary emission is conversion electrons of discrete energies (Table 2). These are also accompanied by an excellent gamma photon for monitoring distribution. The limited penetration of conversion electrons theoretically should reduce the absorbed dose to the red marrow. Studies in animals (Srivastava et al., 1985) demonstrated that the stannic form of Sn-DTPA [Sn-117m (4+) DTPA)] behaved much differently from the stannous form [Sn-117m (2+) DTPA]. It was not rapidly excreted into the urine, as expected, but it is taken up and retained almost exclusively into the bone. Further studies (Oster et al., 1995) 
showed that its behavior mimicked that of Tc-99m MDP in certain pathological conditions. The biodistribution was studied in a group of patients with advanced metastatic disease from various primary malignancies (Atkins et al., 1993).

Table 4 - Dosimetry of bone agents (Srivastava et al., 1998)

\begin{tabular}{lccl} 
& BoneRed & $\frac{\text { Radiation Dose, rad } / \mathbf{m C i}}{\text { Bone/Marrow Dose }}$ & \\
& Surfaces & Marrow & Ratio \\
\hline Strontium-89Cl & 63.0 & 40.7 & 1.6 \\
Rhenium-186 HEDP & 7.0 & 3.0 & 2.3 \\
Samarium-153 EDTMP & 15.4 & 2.8 & 5.5 \\
Tin-117m Stannic DTPA & 65.1 & 9.8 & 6.6 \\
\hline
\end{tabular}

The disappearance rate from blood appeared to be considerably slower than other bone agents and urinary excretion slower. However, because of its rather long physical half-life relative to these biologic parameters, this is not a problem for radiation absorbed dose estimates. Once localized in bone, the $\mathrm{Sn}-117 \mathrm{~m}$ appears to remain fixed with no or extremely slow release other than through physical decay (Atkins et al., 1993; Atkins et al., 1995). Approximately $70 \%$ is taken up by bone, but this is highly variable and depends on the extent of disease. Imaging studies have shown no focus of uptake other than bone. The biologic parameters are shown in Table 5.

\section{Therapy of Cancer in Bone}

The compounds discussed above have been considered primarily as agents to provide pain palliation in patients with far advanced metastases involving bone. The requirements for achieving this purpose are rather modest. It is not necessary to obtain much tumor regression and it is desirable to avoid significant toxicity. Therefore, for achieving pain palliation, it is not necessary to administer the highest doses possible. However, there are hints that more than just pain palliation can be achieved in the appropriate clinical situation. Our data indicate that an earlier onset of response occurs with higher levels of administered tin-117m activity (Srivastava et al., 1998). The Trans-Canada Study performed with high doses of strontium-89 in patients with relatively early metastatic disease of the prostate demonstrated that, as an adjuvant to external beam treatment, the interval to new painful metastases could be significantly lengthened (Porter et al., 1993).

In addition, others have demonstrated reversal of changes on the radionuclide bone imaging study with strontium-89 (Robinson et al., 1989).
Radiographs following radionuclide therapy have shown healing of lytic metastases (Friedell and Storaasli, 1950) thus demonstrating that tumor regression actually can occur. It has also been shown that treatment of earlier disease is more successful than the treatment of more advanced disease. In another study (Liepe et al., 2000), it was also shown that there was a significant reduction of the mass of bone metastases one year after rhenium-186-HEDP pain palliation therapy. Prolongation of survival has been reported using very high doses $(2.5 \mathrm{mCi} / \mathrm{kg})$ of samarium-153 EDTMP (Collins et al., 1993). This has been attained at the expense of increased morbidity as evidenced by greater increase in myelotoxicity.

On the basis of these findings it is reasonable to look at these agents in situations otherthan for bone pain palliation. They may be very useful as adjuvant to external beam radiation therapy and chemotherapy. In primary bone malignancy the use of radionuclide therapy as an adjuvant to surgery may prevent or at least delay the appearance of metastatic disease.

Earlier application of these agents in a prophylactic mode appears warranted. Their ease of administration and relative lack of toxicity present a strong argument for this approach. If higher doses do prove to be advantageous, then that agent with the lowest toxicity should be considered as the most appropriate candidate. Tin$117 \mathrm{~m}$ stannic DTPA appears to be the agent of choice if future studies (an extended Phase II/Phase III clinical trial, temporarily halted, is expected to restart soon) continue to demonstrate reduced toxicity compared to the other agents, in particular strontium-89 and samarium-153. In summary, going beyond bone pain palliation, the use of these bone-seeking radiopharmaceuticals to 
actually treat the primary/metastatic cancer in bone is considered to be a very attractive prospect.

Table 5 - Myelotoxicity Levels ${ }^{1}$ of Radiopharmaceuticals for Bone Pain Palliation (Srivastava et al., 1998)

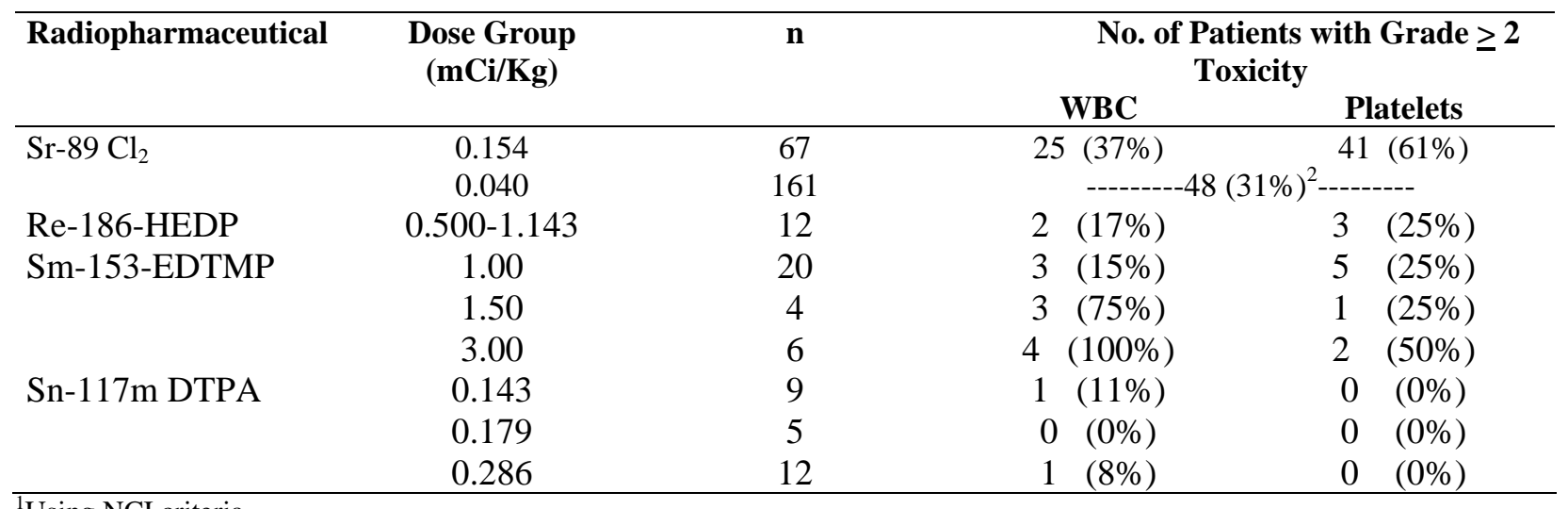

${ }^{1}$ Using NCI criteria

${ }^{2}$ Only hematological toxicity@ grade $\geq 2$ mentioned.

Table 6 - Biopharmacokinetics of Sn-117m(4+)DTPA (Krishnamurthy et al., 1997).

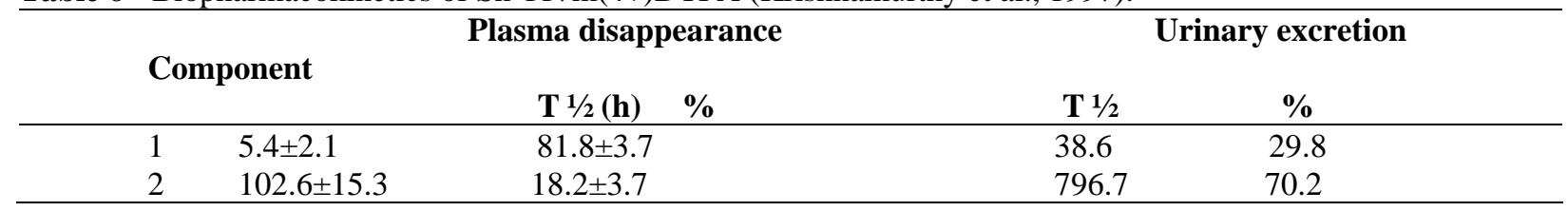

Extending the use Tin-117m (4+) DTPA for treating primary or metastatic bone cancer as mentioned above appears promising due to its better safety profile (Bishayee et al., 2000). However, higher doses of tin- $117 \mathrm{~m}$ will be required, and thus of DTPA which, in the current formulation, is used in a 20-fold molar excess over tin (Srivastava et al., 1998). For a hypothetical 100 $\mathrm{mCi}$ therapeutic dose of $\mathrm{Sn}-117 \mathrm{~m}$ (assuming current average specific activity of $10 \mathrm{mCi} / \mathrm{mg}$; 20:1 DTPA to tin) at product expiration of $45 \mathrm{~d}$ or $\sim 3 t^{1} / 2$, which is the worst case scenario, one may end up having to inject $>5 \mathrm{~g}$ of DTPA. In order to circumvent the potential toxic effects from such large amounts of DTPA, the possibility of reducing the ratio of DTPA to tin in the final formulation, without affecting its biological properties, has been investigated. In earlier investigations, HPLC using a $7.5 \times 75 \mathrm{~mm}$ DEAE column and an inverted parabolic gradient using 0.05-0.4M pH 4.5 phosphate buffer ( $\mathrm{K}^{\prime}$ values: $\mathrm{Sn}$ $117 \mathrm{~m} \mathrm{DTPA}=1$; DTPA $=4.6$ ) provided a suitable method for removal of excess free DTPA (Srivastava et al., 1998). Later, the method was further optimized $(\geq 90 \pm 5 \%$ recovery $)$ using AG3X4 (0.3M NaCl/0.02M $\left.\mathrm{NaH}_{2} \mathrm{PO} 4\right)$ or P-2 Biogel $\left(0.15 \mathrm{M} \mathrm{NaCl} / 0.01 \mathrm{M} \mathrm{NaH}_{2} \mathrm{PO}_{4}\right)$. In mice, it was shown that there is no significant difference in the biodistribution of HPLC purified (3:1) Sn$117 \mathrm{~m}$ DTPA compared to the original 20:1 preparation. This study was a test for the hypothesis that once the tin is firmly chelated, it may even be possible to isolate the 1:1 chelate without compromising its shelf life or biological properties. In addition to utilizing the modified chromatographic purification scheme, a new direct and more convenient radiosynthetic method to prepare $1: 1 \mathrm{Sn}-117 \mathrm{~m} \mathrm{(4+)DTPA}$ chelate, both under organic and aqueous conditions was recently developed (Li et al., 2001; Srivastava et al., 2002). The direct synthesis of the 1:1 chelate (in an organic medium; the methodology was similar using aqueous conditions) was optimized as follows. Metallic Sn-117 or Sn-117m (0.10mmol) was dissolved in $10 \mathrm{ml}$ conc. $\mathrm{HCl}$ under an $\mathrm{Ar}$ or $\mathrm{N}_{2}$ atmosphere. To solid DTPA was added the tin solution in a molar ratio of 1.0 tin to 1.2 DTPA. After the DTPA was dissolved (5 min), water and 
$\mathrm{HCl}$ were removed under vacuum, and then $20 \mathrm{ml}$ $\mathrm{CH}_{2} \mathrm{Cl}_{2}$ was added. After overnight reaction (ultrasonic bath), the sample was evacuated to dryness. The solid was taken up in $10 \mathrm{ml}$ water, heated at $100^{\circ} \mathrm{C}$ for $30 \mathrm{~min}$, cooled, $\mathrm{pH}$ adjusted to 4.2 , and reheated at $100^{\circ} \mathrm{C}$ for $30 \mathrm{~min}$. Complete conversion to $\mathrm{Sn}-117 \mathrm{~m}(4+)$ DTPA was assured by $\mathrm{H}_{2} \mathrm{O}_{2}$ oxidation. The structure of the $1: 1$ chelate (single crystal from aqueous solution) was determined by x-ray crystallography (Fig. 1) and by $\mathrm{C}-13 \mathrm{NMR}$ in $\mathrm{D}_{2} \mathrm{O}$. Mouse biodistribution data for the original (20:1), HPLC-purified (1:1), and synthetic $1: 1$ preparations were obtained at 0,6 , and 23 (or 30) d following storage at $22^{\circ} \mathrm{C}$ and shown to be identical to that of the $20: 1$ clinical formulation. (Table 7).

The $\mathrm{x}$-ray crystal structure of the synthetic 1:1 chelate (Fig. 1) showed an 8-coordinate chelate with three amino and five carboxyl groups bound to the tin atom $\left[\mathrm{H}(\mathrm{SnDTPA}) \cdot 3 \mathrm{H}_{2} \mathrm{O}\right.$ crystals; orthorhombic system, space group Pbca with cell constants $\mathrm{a}=14.07(3), \mathrm{b}=12.15(3), \mathrm{c}=23.15(3)$, $[\mathrm{Z}=8]$. Carbon-13 NMR in $\mathrm{D}_{2} \mathrm{O}$ [178.81(2), 175.87(2), 72.48(1), 64.21(4), 59.23(2), 57.7(1), $57.0(2)]$ showed that the octadentate structure was preserved in solution as well (Srivastava et al., 2002).

The availability of the well characterized 1:1 chelate will facilitate mechanistic studies of tissue localization of Sn-117m DTPA and expand its therapeutic usefulness. Studies for the production of higher specific activity and no-carrier-added tin- $117 \mathrm{~m}$, which are in progress (Toporov et al., 2006; Ermolaev et al., 2006), will further expand the usefulness of this isotope to labeling various receptor binding molecules and various other bioengineered molecular constructs based on monoclonal antibodies, peptides, and others, for application to targeted radionuclide therapy.

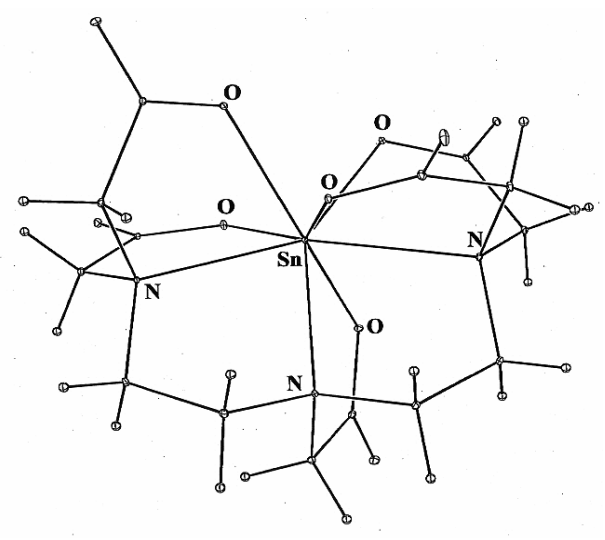

Figure 2 - ORTEP Plot (x-ray crystal structure) of Sn (4+) DTPA Complex [47].

\section{Radiation Synovectomy}

Radiation synovectomy (radiosynoviorthesis) is an attractive alternative to chemical or surgical synovectomy for the treatment of inflammatory synovial disease, including rheumatoid arthritis, as well as to some extent, osteoarthritis. The procedure entails a single injection of a betaemitting radiopharmaceutical directly into the synovium to control and ablate inflammation. The injected agents, typically colloids or larger aggregates, are assumed to be rapidly phagocytized by synoviocytes and then distributed within the synovium, primarily at the surface. The most common agents investigated have been radiocolloids or macroaggregates employing beta emitters of a wide energy range, e.g., Y-90, $\mathrm{Au}-$
198, Dy-165, Re-186, Er-169, etc. (Deutsh et al., 1993; Modder, 2001). While these agents have shown good results, they are approved for clinical use and widely utilized in Europe (Modder, 2001; Chinol et al.,2003) but not in the United States. All display some degree of leakage of the radionuclide from the joints leading to the possibility of increased radiation dose to normal organs. The size of these radiolabeled particles cannot be adequately controlled during formation, and it is assumed that small $(<10 \mu \mathrm{m})$ particles leak from the synovium over time. However, a new type of particle, made from hydroxyapatite (HA), a natural constituent of bone, has become commercially available in various controlled sizes ranging from $1-80 \mu \mathrm{m}$. Research interest has 
thus focused recently on incorporating HA particles into new agents for radiation synovectomy. Initial studies in rabbits with antigen-induced arthritis (AIA) using Sm-153 labeled HA showed minimal leakage of activity
(0.09\% over four days) from the treated joint compared to leakage rates obtained with other radiocolloid agents (5-45\%). Results with Re-186HA, however, showed $3.05 \%$ leakage over four days (Chinol et al., 1993).

Table 7 - Biodistribution (\%ID/g at 24h in mice, $\mathrm{n}=5$ ) of Various Sn-117m DTPA Preparations (Li et al., 2001; Srivastava et al., 2002)

\begin{tabular}{llllll}
\hline Sn-117m DTPA Used & Blood & Liver & Spleen & Kidney & Bone \\
\hline Original (20:1) & $0.015 \pm 0.00$ & $0.30 \pm 0.05$ & $0.09 \pm 0.01$ & $0.75 \pm 0.07$ & $15.14 \pm 1.15$ \\
Purified (1:1), AG 3X4 (6d) & $0.016 \pm 0.00$ & $0.23 \pm 0.05$ & $0.11 \pm 0.02$ & $0.87 \pm 0.09$ & $15.33 \pm 1.62$ \\
Purified (1:1), AG 3X4 (23d) & $0.016 \pm 0.00$ & $0.36 \pm 0.06$ & $0.09 \pm 0.02$ & $0.76 \pm 0.03$ & $13.02 \pm 1.48$ \\
Purified (1:1), P-2 & $0.015 \pm 0.00$ & $0.28 \pm 0.02$ & $0.08 \pm 0.01$ & $0.96 \pm 0.17$ & $14.97 \pm 1.74$ \\
Synthetic (1:1) (30d) & $0.018 \pm 0.01$ & $0.29 \pm 0.02$ & $0.06 \pm 0.01$ & $0.57 \pm 0.08$ & $14.10 \pm 1.91$ \\
\hline
\end{tabular}

EANM procedure guidelines for radiosynovectomy appeared in a recent article in the European Journal of Nuclear medicine (EANM, 2003). The recommended procedures included the radionuclide therapy of joint synovitis or synovial processes with intra-articular injection of colloidal Y-90, Re-186 sulfide, or Er-169 citrate. An IAEA-sponsored multi-national clinical trial [Coordinated Research Project (CRP) on "Comparative Evaluation of the Efficacy of Radiosynovectomy with Conventional Intraarticular Therapy in Rheumatoid Arthritis and Haemophilic Arthropathy (CERAHA)] is also currently in progress to evaluate the relative efficacy of various radiopharmaceuticals including radiocolloids of P-32, Y-90, Re-186, Er-169, and of Sn-117m DTPA (Barrenechea and Amaral, 2003).

The presumed heterogeneous distribution of radionuclide within the synovium for quite some time limited existing agents to only those labeled with high-energy beta emitters. It was presumed that the longer range of these particles is necessary to treat medium to large size joints. However, low-energy beta emitters may be equally or more effective in reducing inflammation for small to medium joints since a much larger radiation dose could be delivered to the synovium without excessive irradiation of surrounding tissue (Srivastava, 1996c). This could be analogous to the effectiveness of the short-range conversion electrons from $\mathrm{Sn}-117 \mathrm{~m}$ for bone pain palliation, compared to the high-energy beta emitter $\mathrm{Sr}-89$
(Srivastava, 1996c; Srivastava and Dadachova, 2001). The only clinical example to date for treating synovial inflammation using a low-energy beta emitter is the use of colloids of Er-169 (avg. beta energy $111 \mathrm{keV}$ ) to treat inflammation in the small joints (EANM, 2003; Boussina et al., 1979). According to the EANM procedure guidelines, Y90 is suited for the knee joint only, Re-186 is suitable for hip, shoulder, elbow, wrist, ankle, and subtalar joints, and Er-169 is suited for metacarpophalangeal, metatorsophalangeal, and digital interphalangeal joints (EANM, 2003).

\section{ACKNOWLEDGEMENTS}

This work at Brookhaven National Laboratory was supported by the United States Department of Energy (DOE), Office of Biological and Environmental Research, Medical Applications Division, and Office of Nuclear Energy (NE), Office of Isotope Programs, under Contract No. DE-AC02-98CH10886.

\section{RESUMO}

Uma variedade de radionuclídeos continua a ser investigada e/ou clinicamente utilizada para diferentes aplicações terapêuticas em medicina nuclear. A escolha de um radionuclídeo, considerando-se sua emissão apropriada, 
transferência linear de energia (LET) e meia-vida física é determinada na maior parte pelo caráter da doença (p.ex., tumor sólido ou doença metastática), e pelo carreador que transporta o radionuclídeo seletivamente para o sítio desejado. Um notável conjunto de informações voltadas para essas considerações tem aparecido na literatura recente. Esse trabalho resume e discute o papel de emissores de elétrons de alta-LET e sua vantagem no tratamento do câncer ou para outras doenças em situações específicas. Abordagens relacionadas com o alívio da dor óssea, a terapia da doença óssea e a sinovectomia por radiação são apresentadas detalhadamente. Projeções para o futuro e os progressos nessas áreas são indicadas. Uma profunda discussão relacionada aos critérios de seleção que são úteis para escolher o radionuclídeo apropriado para que uma aplicação particular seja incluída. O uso de emissores de elétrons de alta-LET é discutido em grande detalhe, com particular ênfase no uso do estanho$117 \mathrm{~m}$, um emissor de elétron de conversão, para várias aplicações terapêuticas.

\section{REFERENCES}

Aldestein, S. J., Manning, F. J. (1995), Isotopes for Medicine and the Life Sciences. Washington, D.C., National Academy Press.

Atkins, H. L., Mausner, L. F., Srivastava, S. C., Meinken, G. E., Cabahug, C. J., Straub, R. F., Cabahug, C. J., Weber, D. A., Wong, C. T., Sacker, D. F., Madjewicz, S. (1993), Biodistribution of Sn$117 \mathrm{~m}(4+)$ DTPA: A new agent for palliative treatment of painful osseous metastases. Radiology, 186, 279-283.

Atkins, H. L., Mausner, L. F., Srivastava, S. C., Meinken, G. E., Cabahug, C. J., D'Alessandro, T. (1995), Tin-117m(4+)DTPA for palliation of pain from osseous metastases: A pilot study. J. Nucl. Med., 36, 725-729.

Barrenechea, E., Amaral, H. (2003), From Gold to Tin: A new coordinated research project on "Comparative evaluation of the efficacy of radiosynovectomy with conventional intra-articular therapy in rheumatoid arthritis and hemophilic arthropathy (CERAHA). World J. Nucl. Med., 2, 155-156.

Bishayee, A., Rao, D. V., Srivastava, S. C., Bouchet, L. G., Bolch, W. E., Howell, R. W. (2000), Marrow Sparing Effects of Sn-117m (4+) DTPA for radionuclide therapy of bone cancer. J. Nucl. Med., 41, 2043-2050.
Boussina, I., Toussaint, M., Ott, H. (1979), A double blind study of Er-169 synoviorthesis in rheumatoid digital joints. Scand. J. Rheumatology, X8, 71-74.

Chinol, M. Vallabhajousula, S., Goldsmith, S. (1993), Chemistry and Biological Behavior of Samarium-153 and Rhenium-186- labeled Hydroxyapatite Particles: Potential Radiopharmaceutical for Radiation Synovectomy. J. Nucl. Med., 34, 1536.

Collins, C., Eary, J. F., Donaldson, G., Vernon, C., Bush, N. E., Petersdorf, S., Livingston, R. B., Gordon, E. E., Chapman, C. R., Appelbaum, F. R. (1993), Samarium-153-EDTMP in bone metastases of hormone refractory prostate cancer: a phase I/II trial. J. Nucl. Med., 34, 1839-1844.

de Klerk, J. M. H., van Dijk, A., van het Schip, A. D., Zonnenberg, B. A., van Rijk, P. P., (1992), Pharmacokinetics of rhenium-186 after administration of rhenium-186-HEDP to patients with bone metastases. J. Nucl. Med., 33, 646-651.

Deutsch, E., Broadack, J., Deutsch, K. (1993), Radiation Synovectomy Revisited. Eur. J. Nucl. Med., 20, 1113 [and references therein].

EANM (2003), Procedure Guidelines for Radiosynovectomy. Eur. J. Nucl. Med., 30, BP12 BP16.

Ercan, M. T., Caglar, M. (2000), Therapeutic radiopharmaceuticals. Cur. Pharm. Design, 6, 10851121.

Ermolaev, S. V., Zhuikov, B. L., Kokhanyuk, V. M., Srivastava, S. C. (2006), Production yields of tin$117 \mathrm{~m}$ from natural antimony target in proton energy range $145-35 \mathrm{MeV}$. Presented at the 9th International Symposium on the Synthesis and Applications of Isotopes and Isotopically Labelled Compounds, Edinburgh, U.K.

Farhangi, M., Holmes, R. A., Volkert, W. A., Logan, W., Singh, A. (1992), Samarium-153 EDTMP: Pharmacokinetics, toxicity and pain response using an escalating dose schedule in treatment of metastatic bone cancer. J. Nucl. Med., 33, 1451-1458.

Fettich, J., Padhy, A., Nair, N., Morales, R., Tamumihardja, M., Riccabonna, G., Nair, G. (2003), Comparative clinical efficacy and safety of phosphorus-32 and strontium-89 in the palliative treatment of metastatic bone pain: Results of an IAEA Coordinated Research Project. World J. Nucl. Med., 2, 226-231.

Firusian, N., Mellin, P., Schmidt, C. (1976), Results of 89Sr therapy in patients with carcinoma of the prostate and incurable pain from bone metastases: a preliminary report. J. Urology, 16, 764-768.

Fossa, S. D., Paus, E., Lochoff, M., Backe, S. M., Aas, M. (1992), ${ }^{89}$ Strontium in bone metastases from hormone resistant prostate cancer: Palliation effect 
and biochemical changes. Brit. J. Cancer, 66, 177180.

Friedell, H. L. and Storaasli, J. P. (1950), The use of radioactive phosphorus in the treatment of carcinoma of bthe breast with widespread metastases to bone. Am. J. Roentgenol., 64, 559-575.

Humm, J. L. (1986), Dosimetric aspects of radiolabeled antibodies for tumor therapy. J. Nucl. Med., 27, 1490-1497.

Katin, M. J., Salenius, S. A. and Blitzer, P. H. et al. (1993), Hematologic effects of Sr-89 treatment for metastases to bone. Proc. Amer. Soc. Clin. Oncol., 3, 12.

Kennedy, J. M., Marinelli, L. D., Woodard, H. Q. (1941), Tracer studies with radioactive phosphorus in malignant neoplastic disease. Radiology, 37, 683-690.

Krishnamurthy, G. T., Swailem, F. M., Srivastava, S. C., Atkins, H. L., Simpson, I. J., Walsh, T. K., Ahmann, F. R., Meinken, G. E., Shah, J. H. (1997), Sn-117m(4+)DTPA pharmacokinetics and imaging characteristics in patients with metastatic bone pain. J. Nucl. Med., 38, 230-237.

Lewington, V. J., McEwan, A. J., Ackery, D. M., Bayly, R. J., Keeling, D. H., Macleod, P. M., Porter, A. T., Zivanovic, M. A. (1991), A prospective, randomized double-blind crossover study to examine the efficacy of strontium-89 in pain palliation in patients with advanced prostate cancer metastatic to bone. Eur. J. Cancer, 27, 954-958.

Li, Z., Meinken, G.E., James, J.L., Srivastava, S.C. (2001), Synthesis and Structural Characterization of the promising therapeutic agent ${ }^{117 \mathrm{~m}} \mathrm{Sn}$ DTPA. $J$. Nucl. Med., 42: 21P.

Liepe, K., Hliscs, R., Kropp, J., Runge, R., Knapp, F. F. Jr., Franke, W. (2003), Dosimetry of ${ }^{188}$ Re-HEDP in human prostate cancer skeletal metastases. J. Nucl. Med., 44, 953-960.

Liepe, K., Kropp, J., Hliscs, R., Franke, W. G. (2000), Significant reduction of the mass of bone metastasis one year after Rhenium-186-HEDP pain palliation therapy. Clin Nucl Med., 25, 901-904.

Mausner, L.F., Srivastava, S.C. (1993), Selection of radionuclides for radioimmunotherapy. Med. Phys., 20, 503-509.

Maxon, H. R., Schroder, L .E., Thomas, S. R., Hertzberg, V. S., Deutsch, E. A., Scher, H. I., Samaratunga, R. C., Libson, K. F., Williams, C. C., Moulton, J. S. (1990), Re-186(Sn)HEDP for treatment of painful osseous metastases: Initial clinical experience in 20 patients with hormoneresistant prostate cancer. Radiology, 176, 155-159.

McEwan, A. J. B. (1994), Radiopharmaceuticals for palliative treatment of painful bone metastases. New Perspec. Cancer. Diagn. Management, 1, 24-31.

Modder, G. (2001), Radiosdynoviorthesis: Involvement of Nuclear Medicine in Rheumatology and Orthopedics, Warlich Druck und Verlagsges, mbH Publishers.Meckenheim, Germany.
O'Donoghue, J. A., Bardiès, M., Wheldon, T. E. (1995), Relationships between tumor size and curability for uniformly targeted therapy with betaemitting radionuclides. J. Nucl. Med., 36, 1902-1909.

Oster, Z. H., Som, P., Srivastava, S. C., Fairchild, R. G., Meinken, G. E., Tillman, D. Y., Sacker, D. F., Richards, P., Atkins, H. L., Brill, A. B., et al. (1985), The development and in-vivo behavior of tin containing radiopharmaceuticals II. Autoradiographic and scintigraphic studies in normal animals and in animal models of disease. Int. J. Nucl. Med. Biol., 12, 175-184.

Pecher, C. (1942), Biological investigations with radioactive calcium and strontium: preliminary report on the use of radioactive strontium in the treatment of bone cancer. University of California Publications in Pharmacology, 11: 117-149.

Porter, A. T., McEwan, A. J. B., Powe, J. E., Reid, R., McGowan, D. G., Lukka, H., Sathyanarayana, J. R., Yakemchuk, V. N., Thomas, G. M., Erlich, L. E. (1993), Results of a randomized phase-II trial to evaluate the efficacy of strontium-89 adjuvant to local field external beam irradiation in the management of endocrine resistant metastatic prostate cancer. Int. J. Radiat. Oncol. Biol. Physics, 25, 805-813.

Quilty, P. M., Kirk, D., Bolger, J. J., Dearnaley, D. P., Lewington, V. J., Mason, M. D., Reed, N. S., Russell, J. M., Yardley, J. (1994), A comparison of the palliative effects of strontium- 89 and external beam therapy radiotherapy in metastatic prostate cancer. Radiother. Oncol., 31, 33-40.

Resche, I., Chatal, J. F., Pecking, A., Dushesne, G., Rubens, R., Fogelman, I., Houston, S., Fauser, A., Fischer, M., Wilkins, D. (1997), A dose-controlled study of ${ }^{153} \mathrm{Sm}$ ethylenediaminetetramethylenephosphonate

(EDTMP) in the treatment of patients with painful bone metastases. Eur. J. Cancer, 33, 1583-1591.

Robinson, R. G. (1986), Radionuclides for the alleviation of bone pain in advanced malignancy. Clin. Oncol., 5, 39-49.

Robinson, R. G. Blake, G. M. and Preston, D. F., McEwan, A. J., Spicer, J. A., Martin, N. L., Wegst, A. V., Ackery, D. M. (1989), Strontium-89: Treatment results and kinetics in patients with painful metastatic prostate and breast cancer in bone. Radiographics, 9, 271-281.

Robinson, R. G., Spicer, J. A., Preston, D. F., Wegst, A. V., Martin, N. L. (1987), Treatment of metastatic bone pain with strontium-89. Nucl. Med. Biol., 14, 219-222.

Srivastava, S. C. (1996), Criteria for the selection of radionuclides for targeting nuclear antigens for cancer radioimmunotherapy. Cancer Biother. Radiopharm., 11, 43-50. 
Srivastava, S. C. (1996), Therapeutic Radionuclides: Making the Right Choice. in Mather, S.J. (ed): Current Directions in Radiopharmaceutical Research and Development, 1996, Dordrecht, The Netherlands, Kluwer Academic Publishers, pp 63-79.

Srivastava, S. C. (1996), Therapeutic Radionuclides: Making the Right Choice. In- Mather, S. J. (ed.). Current Directions in Radiopharmaceutical Research and Development. Kluwer Academic Publishers, Dordrecht, The Netherlands, pp. 63-79.

Srivastava S. C. (1999), Traditional and new isotopes for radioimmunotherapy. in Riva $\mathrm{P}$ (ed): Therapy of malignancies with radioconjugated monoclonal antibodies: Present possibilities and future perspectives, Chur, Switzerland, Harwood Academic Publishers, pp 11-26.

Srivastava, S. C. (2002), Bone-Seeking Therapeutic Radiopharmaceuticals. Braz Arch Biol Technol, 45, 45-56.

Srivastava, S. C., Atkins, H. L. and Krishnamurthy, G. T. et al., Treatment of metastatic bone pain with tin$117 \mathrm{~m}$ stannic DTPA: A phase I/II clinical study. Clin. Cancer Res., 1998; 4: 61-68.

Srivastava, S. C., Dadachova, E. (2001), Recent Advances in Radionuclide Therapy. Seminars in Nucl. Med., 31, 330-341.

Srivastava, S. C., Meinken, G. E., Richards, P., Som, P., Oster, Z. H., Atkins, H. L., Brill, A. B., Knapp, F. F. Jr., Butler, T. A. (1985), The development and invivo behavior of tin containing radiopharmaceuticals I. Chemistry, preparation and biodistribution in small animals. Int. J. Nucl. Med. Biol., 12, 167-174.

Srivastava, S. C., Meinken, G. E., Mausner, L. F., (1994)., Nuclear, chemical, and mechanistic considerations in the use of ${ }^{117 \mathrm{~m}} \mathrm{Sn}$ (IV)-DTPA relative to ${ }^{186} \mathrm{Re}$-HEDP and other agents for bone pain therapy. In- Nicolini, M. et al. (Eds.). Fourth International Symposium on Technetium in Chemistry and Nuclear Medicine. SG Editoriali, Padova, Italy, pp. 287-292.
Srivastava, S. C., Meinken, G. E., James, J. L. (1998), Characterization and In-vivo Testing of HPLCpurified Sn-117m Stannic DTPA Preparations. Eur. J. Nucl. Med., 25, 979.

Srivastava, S. C., Meinken, G. E., Li, Z. (2002), A novel synthetic method for preparing $S n-117 \mathrm{~m}$ Stannic DTPA for therapeutic use. J. Nucl. Med., 43, 372P.

Toporov, Yu.G., Andreeyev, O. I., Vakhetov, F. Z., Gavrilov, V. D., Srivastava, S.C. (2006), High specific activity tin- $117 \mathrm{~m}$ reactor production at RIAR. Presented at the 9th International Symposium on the Synthesis and Applications of Isotopes and Isotopically Labelled Compounds, Edinburgh, U.K..

Turner, J. H., Claringbold, P. G. (1991), A phase II study of painful multifocal skeletal metastases with single and repeated dose samarium-153 ethylenediaminetetramethylene phosphonate. Eur. J. Cancer, 27, 1084-1086.

Volkert, W. A., Goeckler, W.F., Ehrhardt, G.J., Ketring, A. R. (1991), Therapeutic radionuclides: production and decay property considerations. $J$. Nucl. Med., 32,174-185.

Wheldon, T. E. (1994), Targeting radiation to tumors. Int. J. Radiat. Biol., 65, 109-116.

Received: July 31, 2007; Revised: August 25, 2007; Accepted: September 042007. 